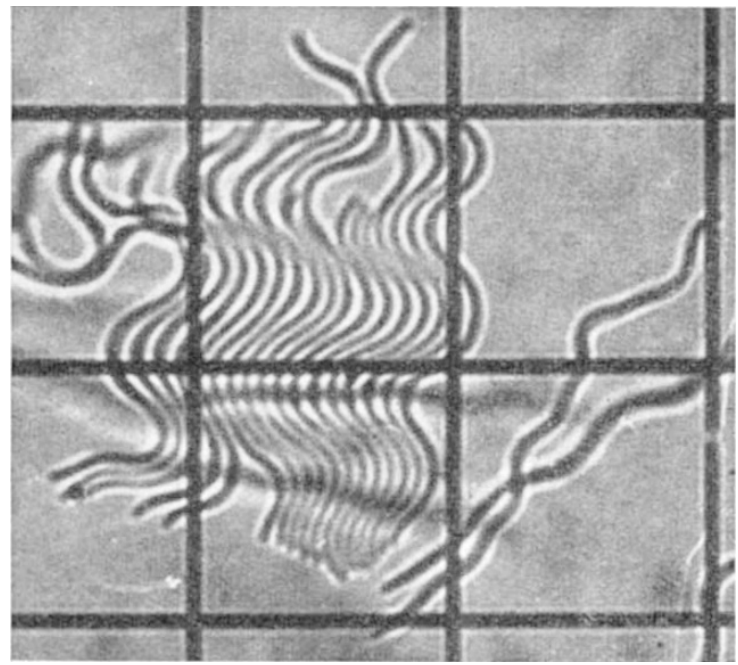

Fig. 2. Photograph of a group of living Cristispira balbianii showing synchronized movements in a thin film of water. The anterior ends of the organisms are attached to a glass slide. The sides of the black grid are $40 \mu$

in water is a formidable mathematical problem which is at present being examined by Sir Geoffrey Taylor.)

The sensitivity of wave form to external mechanical forces is a very widespread phenomenon among undulatory animals. A somewhat specialized but interesting example is shown in Fig. 2, which demonstrates the co-ordinated activity ensuing when two or more active organisms are sufficiently close together to exert mechanical forces on each other. These and other facts suggest that the difference in phase between adjacent regions of an active flagellum is controlled by the external physical forces acting against its surface.

(4) When a large animal (for example, an eel) is undulating in water, some of the energy required to bend the distal regions of the body and to drive these through the water are transmitted (by tho body's own elasticity) from other regions lying nearer the head of the animal. In a flagellum, perhaps $0.5 \mu$ in diameter, moving at $100 \mu$ per second, the amount of energy which can be transmitted in this way is negligibly small compared with that required to move the flagellum against the viscous resistance of the water. Each short unit length of the flagellum must provide the whole of the energy necessary to maintain its own motion.

An application of these four principles to bacterial propulsion leads to the conclusion that the length of a bacterium and the ratio of amplitude to wave-length of its bodily undulations are both too small to sustain an efficient propulsive thrust. On the other hand, if the whole surface of the body were covered by an active sheet able to undulate with the wave-length and amplitude of the 'tails' shown in Pijper's figures, the organism would progress, and if some of this sheet were 'sloughed off' behind the organism, the 'tails' described by Pijper might well result. If the frequency of undulation were of the same order as that of the tail of the spermatozoon of a sea urchin, the waves would only be visible under stroboscopic darkground illumination. A post-mortem degradation of such an active sheet into a series of disoriented fibrillar elements would be in accordance with the behaviour of a wide variety of vibratile structures, and may explain the apparent existence of discrete flagella in electron micrographs of bacteria.
It is difficult to believe that disorientated fibrils such as those revealed by the electron microscope could propel a bacterium unless, during life, the fibrils are orientated in an antero-posterior direction. On the other hand, a series of active flagella in close proximity to each other would most probably develop synchronized movements. It would be very difficult to distinguish a true membranous sheath from a series of parallel filaments if both were propagating waves of identical form and frequency. From this point of view there seems little difference between the two theories.

A note of caution may perhaps be sounded concerning the functional interpretation of the fibrils and other structures revealed by methods which involve the destruction of the flagellum as an active dynamic system. The X-ray diffraction patterns of these fibrils suggest that their molecular structure is not dissimilar to that of hair and other natural fibres. The central problem is to endow such a system with three essentially dynamic properties : (1) the generation of internal bending couples ; (2) the maintenance of phase difference in dynamical activity along the fibril; (3) the generation of free mechanical energy along the whole length of the fibril. To provide a picture of intra- or inter-molecular forces capable of meeting these requirements would be a major contribution to biology : at present, it is only possible to speculate how far internal bending couples could be generated within a long fibrillar molecule by a redistribution of intramolecular groupings of the type postulated by Meyer and $\mathrm{Mark}^{2}$ and others for muscular contraction, the function of the vertebral column of the eel being performed by mutually repellent charges and that of the muscles by attractive charges. Such a system, if sensitive to mechanical stretch, would at least have some of the properties of an active flagellum, although there would still remain the necessity for periodic changes in the distribution of the charges concerned.

"The Nature of the Bacterial Surface", edited by A. A. Miles and

N. W. Pirie (Oxford Univ. Press, 1950).

2 M.cyer, K. H., and Mark, H., Nature, 16\%, 736 (1951).

\section{GEORGE FRANCIS FITZGERALD, I851-190| \\ CENTENARY MEETING AT THE ROYAL DUBLIN SOCIETY}

G

F. FITZGERALD is unique in the history of modern science in that the fundamental hypothesis for which he is most remembered is one upon which he himself published nothing. This is the hypothesis that a moving body is contracted in the direction of its motion. Its historical significance can scarcely be over-estimated. For it asserts that the length assigned by an observer to a rigid body depends not only upon the body but also upon its relationship to the observer. It was therefore an attack upon the whole classical concept of space, according to which space possesses a geometry identical with that of a classical rigid body, the latter being supposed the same for all observers. FitzGerald's suggestion was the first of those which led to the emergence of 'post-classical' physics.

FitzGerald's priority in this matter has never been questioned. As is well known, he made the suggestion in order to account for the null result of the Michel- 
son-Morley experiment. Sir Oliver Lodge has told ${ }^{1}$ how he had it from FitzGerald in $1892 ; H$. A. Lorentz made the suggestion independently shortly afterwards, but then acknowledged FitzGerald's priority.

FitzGerald was born on August 3, 1851, the son of William FitzGerald, afterwards Bishop of Cork and later of Killaloe. His mother's brother was George Johnstone Stoney, who also anticipated a fundamental concept of modern physics, the electron, and to whom is due the current use of the term. As boys, FitzGerald and his brothers were educated at home, one of their teachers being a sister of George Boole. FitzGerald entered Trinity College, Dublin, in 1867, became a Fellow in 1877 and Erasmus Smith professor of natural and experimental philosophy in 1881. 'These appointments he held until his death in 1901, at the age of forty-nine.

FitzGerald was one of the prominent figures in late nineteenth century science. $\mathrm{He}$ is noted for a great deal more than the one hypothesis already mentioned; in fact, he is one of the most frequently quoted authors in Sir Edmund Whittaker's "History of the Theories of the Aether and Electricity" (second edition, Edinburgh, 1951). As early as 1883 he showed theoretically" that electromagnetic waves "of as little as $10 \mathrm{~m}$. wavelength or less" could be generated by oscillating electric circuits ; and it is interesting to recall that in 1898 he took part in Marconi's demonstration in Dublin Bay of ship-to-shore wireless transmission which resulted in the first newspaper publication (in the Dublin Evening Mail) of news obtained by wireless. In 1888 he anticipated theoretically the modern use of the coaxial cable and wave-guides ${ }^{3}$. These are examples of his gift for throwing out brilliant suggestions which were much in advance of his time and which he himself did not pursue very far. Indeed, Oliver Heaviside wrote, "He had, undoubtedly, the quickest and most original brain of anybody. ... He saw too many openings. His brain was too fertile and inventive. I think it would have been better for him if he had been a little stupid-I mean not so quick and versatile, but more plodding. $\mathrm{He}$ would have been better appreciated, save by a few." But his brilliance and versatility operated against the development of his own work also by laying him open to unceasing consultation by others, and he perhaps erred on the side of generosity in the help he gave. In addition, he played an influential part in the furtherance of university and technical education in Ireland.

A large proportion of FitzGerald's papers appeared in the Proceedings of the Royal Dublin Society, and he was from 1881 until 1889 honorary secretary of that body. On October 30, 1951, the Society devoted one of its scientific meetings to the celebration of the centenary of his birth. The chair was taken by the president, Major A. McMorrough Kavanagh, and afterwards by Dr. A. Went (committee-chairman). 'There were present one of FitzGerald's sons, Sir Raymond FitzGerald, a daughter, Mrs." Scott, and other relatives. The Physical Society of London, of which FitzGerald had been president in 1892, was represented by Prof. K. G. Emeléus. Messages were received from the Institution of Electrical Engineers, of the Irish Section of which FitzGerald was the first chairman (1899), from Sir Edmund Whittaker and from Dr. G. F. C. Searle, who had known him personally. The Provost of Trinity College, Dublin, Dr. E. H. Alton, gave personal reminiscences of FitzGerald, and quoted tributes to his character as a man in which his contemporaries had dwelt especially upon his complete freedom from considerations of his own self-interest. Dr. Alton also showed photographs ${ }^{4}$, taken by J. Joly, of FitzGerald's pioneering experiments in human flight in a glider constructed by O. Lilienthal in Germany. Prof. F. E. W. Hackett (University College, Dublin) spoke of "FitzGerald as revealed by his letters to Heaviside". Photostat copies of the letters, presented by the Royal Institution, were on view at the meeting. Since the exchange of views between the two men depended almost entirely upon their correspondence, these letters give much insight into the working of FitzGerald's mind. They are enlivened by that sparkle which, according to Praeger and Lodge, characterized his talk at a lunch-table or at a scientific discussion.

'The main theme of the meeting was, however, the significance of the FitzGerald-Lorentz contraction. The noteworthy feature was the demonstration that this is still a live subject, the papers contributed being far from mere historical reviews. For it cannot be denied that there is at the present time a widespread reaction against the theory of general relativity on account of the difficulty of applying it to problems of interest, the still greater difficulty of knowing what the theory really signifies, and the lack of success of 'unified field-theories'. This situation itself was not discussed. It is mentioned here because it is resulting in the realization that there is still important funda. mental work to be done in the special theory of relativity (using this term without reference to any one particular formulation of the theory) which is free from the objections to the general theory. The papers read at the meeting can be regarded as part of the outcome of the situation.

The chief address was by Dr. Herbert E. Ives (New York). He started his comprehensive and critical historical review with a precise statement of the relation of FitzGerald's hypothesis to the Michelson-Morley experiment. He recalled how FitzGerald's contemporary, Sir Joseph Larmor, had accepted the hypothesis and had remarked in 1900 that it required as a consequence the phenomenon of 'time-dilatation'. Dr. Ives emphasized the really fundamental step which FitzGerald made in compelling us to take explicit account of the behaviour of measuring instruments and also to scrutinize the language employed, which had been developed on the assumption of invariant instruments. 'Thus he saw in FitzGerald's hypothesis "the germs of what are now called 'the operational principle' and 'semantics' ".

Dr. Ives proceeded to an account of the work of H. A. Lorentz and Henri Poincaré. Lorentz endeavoured to extend to all electrodynamic phenomena the invariance with motion found in the MichelsonMorley experiment. Seeking a principle that would comprehend all the particular ideas of Lorentz, Poincaré formulated ${ }^{5}$ in 1904 "the principle of relativity, according to which the laws of physical phenomena should be the same, whether to an observer fixed, or for an observer carried along in a uniform motion of translation, so that we have not and could not have any means of discovering whether or not we are carried along in such a motion". Poincaré then gave the Lorentz transformation in the form in which it is known to-day, though this was a modification of Lorentz's original form.

Dr. Ives then described his own $^{6}$ 'operational' derivation of this transformation, assuming only Poincaré's relativity-principle and the accepted result that the velocity of light is independent of the 
velocity of its source. In terms of his operationally defined quantities, the equations are complicated. "This is the price we have to pay," he said, "for equations which tell a complete and unambiguous story in symbols all of which have a definite operational meaning." However, a change of variables does, in fact, yield the standard form of the Lorentz transformation. One takes it that this substitution provides an explicit operational representation of the clock-synchronization, etc., required, but less carefully examined in more familiar treatments. Dr. Ives went on to a careful inspection of the "principle of the constancy of the velocity of light" which, as usually understood, he rejects.

$\mathrm{He}$ described also his well-known experimental verification ${ }^{2}$ of the time-dilatation using the spectra of canal rays, following a suggestion originally made by J. Stark ${ }^{8}$ and employing A. J. Dempster's method of accelerating canal-ray particles.

Dr. G. J. Whitrow (Imperial College of Science and Technology, London) contributed a paper on "The FitzGerald-Lorentz Contraction Phenomenon and the Theories of the Relativity of Galilean Frames". In the author's absence, it was described by Prof. W. H. McCrea. Dr. Whitrow started by quoting Bishop Berkeley's criticism of Newton's introduction of absolute motion into natural philosophy. The dilemma of Newtonian physics was that, while it held good for all Galilean frames in uniform relative motion, the phenomena of rotation seemed to demand an absolute standard of rest. In nineteenth-century physics this was provided by postulating the luminiferous æther. But the Michelson-Morley experiment demonstrated the impossibility of measuring linear motion through the ather. Einstein's formulation of the theory of special relativity again replaced the æther by empty space, but again gave no explanation of rotational phenomena. E. A. Milne's theory of kinematic relativity and worldstructure offered a solution of the difficulty. In his view, the whole system of galaxies, or rather the substratum which in the theory represents the smoothed-out system of galaxies, provides at every point of space an absolute standard of rest and nonrotation. But the theory ${ }^{\circ}$ is complicated by a distinction between fundamental and subsidiary Galilean frames. Dr. Whitrow now proposes a modification of Milne's work which restores to it the formalism of special relativity. The consequence of the work of Milne and Whitrow is thus to provide special relativity with a cosmological background. Dr. Whitrow also related the problem to a view of the philosophy of science which he has recently developed ${ }^{10}$.

A paper by Prof. W. H. McCrea (Royal Holloway College, University of London) on "The FitzGeraldLorentz Contraction-some Paradoxes and their Resolution" dealt with the problem of the rigid rod in special relativity theory. According to the theory, the contraction denotes no intrinsic physical change in a moving rod. Nevertheless, an observer can 'trap' the rod in the contracted state and exhibit it as having undergone such a change. If we define a rigid rod as one through which an impulse can travel with maximum permitted speed (that is, the speed of light), then it becomes clear how such a physical change is produced in the process of stopping the rod. If it is stopped at the forward end, then the shortest length momentarily attained is, in fact, less than that given by the FitzGerald factor. It can be shown that the kinetic energy just suffices to supply the energy of compression without dissipation ; con- sequently the 'rigid' rod can be regarded as being also perfectly elastic.

Prof. J. L. Synge (Dublin Institute for Advanced Studies), in his paper on "Effects of Acceleration in the Michelson-Morley Experiment", dealt also, but more generally, with the rigid-body problem. The definition he gave was in a form due to his pupil, Mr. G. H. F. Gardner, and is based upon the concept of a 'drag-point' in the body, together with a condition requiring that any particle of the body responds to the behaviour of the drag-point only with a delay corresponding to the time of travel of light from the point to the particle. This appears to reduce to McCrea's definition in the case of a one-dimensional body. The definition enables one to study the motion of a rigid body in accelerated motion relative to a Galilean frame. As Prof. Synge pointed out, the Michelson-Morley experiment is one upon the behaviour of such a body, the instrument being in accelerated motion on account of the rotation and revolution of the earth. He stated that Gardner's hypothesis predicts a null result for the MichelsonMorley experiment if the interferometer is loosely attached to the earth, as it appears to have been in the latest repetitions of the experiment which have, in fact, given the null result. On the other hand, if the instrument is rigidly attached to the earth, then the hypothesis predicts a definite result about three times that reported by Dayton C. Miller in his particular repetition of the experiment ${ }^{11}$. The provisional interpretation is that Miller's interferometer had sufficient rigid connexion with the earth to show part of the acceleration effect predicted by the new theory. But, as Prof. Synge took care to state, judgment must be suspended until the theory is tested by specially designed experiments.

All these papers will be published in a special number of the Proceedings of the Royal Dublin Society, and will be found to contain much more information than there has been space even to mention in this report.

W. H. MCCrea

${ }^{1}$ Lodge, O., Nature, 46, 164 (1892) ; Phil. Trans., A, 184, 727, 479 (1893) ;'Brit. Assoc. Report, 1913, p. 25.

${ }^{2}$ FitzGerald, G. F., "Scientifle Writings", 129 (edit. by J. Larmor, 1902).

${ }^{8}$ FitzGerald, G. F., "Scientiflc Writings". 237.

"Bailey, K. C., published in "History of Trinity College, Dublin, 1892-1945"', 209 (Dublin, 1947).

'Poincaré, H., "La Revue des Idées", 801 (Paris. 1904); C.R. Acad. Sci., Paris., 140, 1504 (1905); Pálermo Rend., 21, 166 (1906).

- Ives, H. E., J. Opt. Soc. Amer., 39, 757 (1949); Proc. Amer. Phil. Soc., 95, 125 (1951).

'Ives, H. E., and Stilwell, G. R., J. Opt. Soc. Amer., 28, 215 (1938); $31,369(1941)$.

8 Stark, J., see Ives, H. E., J. Opt. Soc, Amer., 37, 810 (1947).

Milne, E. A., Proc. Roy. Soc., A, 200, 219 (1950).

${ }^{10}$ Whitrow, G. J., Brit. J. Phil. Sci., 2, 67 (1951).

${ }^{11}$ Miller, D. C., Science, 77, 587 (1933).

\section{RABBIT CONTROL IN AUSTRALIA : PROBLEMS AND POSSIBILITIES}

CHE story of the rabbit in Australia is so well known, so familiar an instance of the spread of an innocent introduction to plague dimensions, that fresh turns in its course must be spectacular to become news. For most of the world beyond Australia, there is the pest, and there are the problems of its control. Even in Australia itself, there has been perhaps a sense of inevitability that this prolific competitor for grazing must embarrass agricultural production, impede attempts to raise both old- 